\title{
Comparative structural vibration analysis of machinery and GFRP with Al7075
}

\author{
K. Vinoth Kumar ${ }^{1}$, T.G. Loganathan ${ }^{1}$, A. Bharath ${ }^{1}$, B. Shyam Sundar ${ }^{1}$ and K. K. Abishek ${ }^{1}$ \\ ${ }^{1}$ Dept. of Mechanical Engineering, RMK College of Engineering and Technology, Puduvoyal, \\ Thiruvallur, India.
}

\begin{abstract}
The current scenario of the industries is that the major losses in efficiency of a machine are due to vibration and friction. To reduce the detrimental effects of vibration we need to decrease the frequency and amplitude of vibration or completely eliminate vibration. To do that one must quantify vibration that already occurs in machinery and structural components. Which is the aim of this paper. The intention of the paper is to obtain and characterize the vibration signature of equipment used in a company and composite material. We have designed a setup to vibrational properties composites, vibrational signature of industrial equipment .To study vibration properties, micro-electrical mechanical systems (MEMS) based accelerometers are used to measure acceleration of the material about the datum when displaced. The data obtained is processed in MATLAB using ARDUINO relayed to computer to convert the data to frequency spectra using Fast-Fourier transforms (FFT). We ultimately compared the vibrational properties of two lathes used at a metal fabrication plant operating at different Conditions and quantified the vibration results using Fast Fourier Transforms (FFT) algorithm. The vibration signatures of a composite is studied along with which various properties like Damping Coefficient, Free Vibration, GFRP, Natural Frequency applications are studied.
\end{abstract}

\section{Introduction}

Vibration is one type of a mechanical property where oscillations occur with or without repeated motion about a equilibrium position. The oscillations can be periodic, non periodic and many other types. But, vibration is not desired because energy is lost through vibration and noise is created. The studies of sound and vibration are closely related. Sound, or pressure waves, is generated by vibrating structures (e.g. vocal cords); these pressure waves can also induce the vibration of structures (e.g. ear drum). Hence, attempts to reduce noise are often related to issues of vibration. Design improvements can be done to reduce vibrations. Vibration and friction reduce the efficiency of a machine. Some of the reasons for vibrations are Imbalance, misalignment, wear and looseness and many more. Composite materials are widely used from aerospace industry to toys, and in such circumstances it is imperative to study vibrational properties of composite materials. Modern composite material has become viable alternatives to conventional substances as they have high strength to weight ratios in addition to other properties which render them to have a high

* Corresponding author: skvinothpec@gmail.com 
structural integrity and stability. Fiber Reinforced Plastics, an essential composite used in modern manufacturing, can be classified as bidirectional FRP's, unidirectional FRP's, quad axial FRP's, twill FRP's etc. During vibrations, the resonance amplitude is greatly influenced by damping at each mode. During design of composite material, some properties of importance to be considered are static and dynamic properties in addition to damping factor. In testing, vibration frequencies show progressively increasing normal probability distribution function with rising amplitude, and the curve can be classified as dual peak. nonlinear vibration analysis can be performed using a $\mathrm{C}^{0}$ assumed strain interpolated finite element plate model based on Reddy's third order theory, it was found that nonlinear frequencies show increasing non-Gaussian probability density function with increasing amplitude of vibration and show dual peaks at high amplitude ratios. ${ }^{[1]}$ MEMS accelerometer is used to monitor the vibrations of the machine and the self test features. Impulse response of the accelerometer is measured with the help of output pin using an oscilloscope. ${ }^{[2]}$ Vibration sensor is used convert mechanical load to an electrical signal and to enhance vibration sensor performance. ${ }^{[3]}$ In future, piezo-electric sensors, actuators and the like can be integrated into 'intelligent structures' to achieve positive vibration control. ${ }^{[4]}$ The vibration analysis systems and wear debris analysis can be integrated into industrial machinery, allowing for 'intelligent maintenance' programs to be implemented. The 'intelligent maintenance' programs allow for planning and assigning maintenance tasks to achieve a lean maintenance function in the firm, reducing waste (muda)- waste such as waiting due to equipment failure, maintenance inventory etc. can be avoided. ${ }^{[5]}$

\section{Vibration Measurement Setup}

The components used to capture vibrational properties of composite materials and industrial machinery using micro electrical mechanical systems based sensors are Arduino open source microcontroller and accelerometer and a stand has been designed to hold the specimen. The composite material has been fabricated according to ASTM standards for composite material vibration testing. The design of the stand has been shown in the diagram. The base of the stand is fabricated from M/S steel sheet of thickness $8 \mathrm{~mm}$. The base table has a railing mechanism attached to the top to hold a plunger. A plunger has been used to apply a uniform displacement and hence cause forced vibrations on the composite materials. A plunger has been explicitly used to apply a constant load. The Arduino Integrated development environment and MATLAB, which is a numerical computing environment that is built around an easy scripting language, which makes MATLAB perfect for quick testing and data analysis.

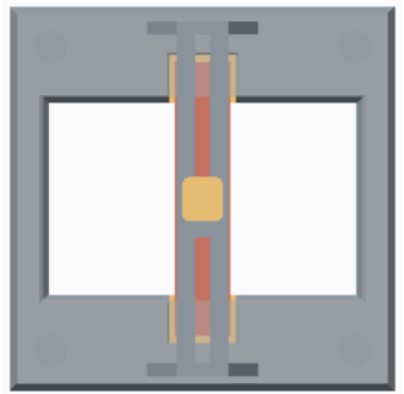

Fig. 1. Top view of the vibration machine 

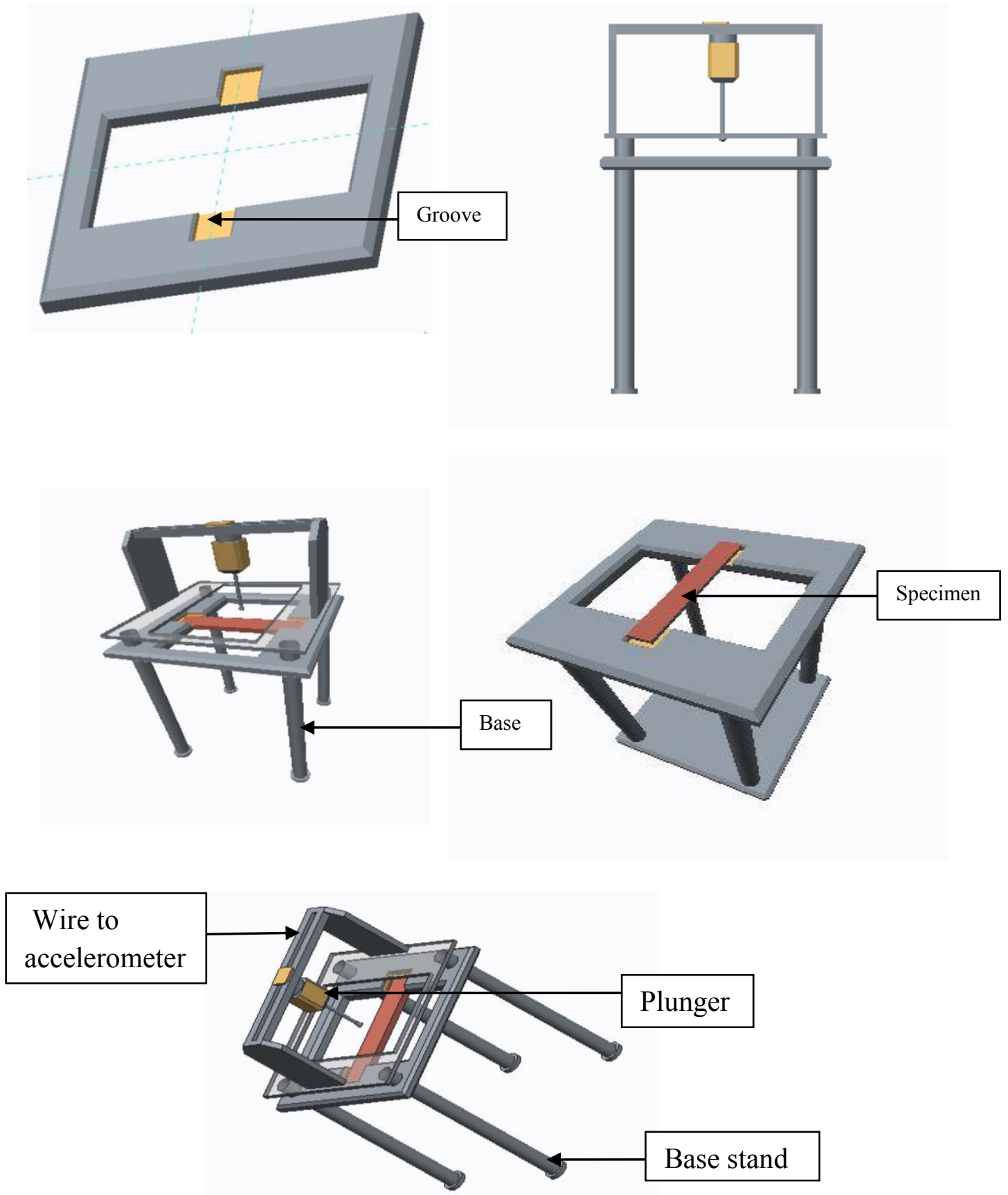

Fig. 2. (i) Specimen holding base with groove, (ii) Front view of vibration machine, (iii) 3-D view of setup, (iv) specimen placed in base, (v) different view of machine. 


\subsection{Design Calculation for plunger used}

The force applied by the plunger is constant. Hence, the force applied has to be calculated. The dimension of diameter of the plunger tip is $5 \mathrm{~mm}$. This is

$$
\text { pressure }=\frac{\text { force }}{\text { area }} \gg 8 \text { bar }=\frac{x}{0.000025} \gg x=20 \text { newtons }
$$

Hence the plunger applies a load of 20 Newton force on the composite material. The plunger provides a displacement of $5 \mathrm{~mm}$ on the composite material specimen.

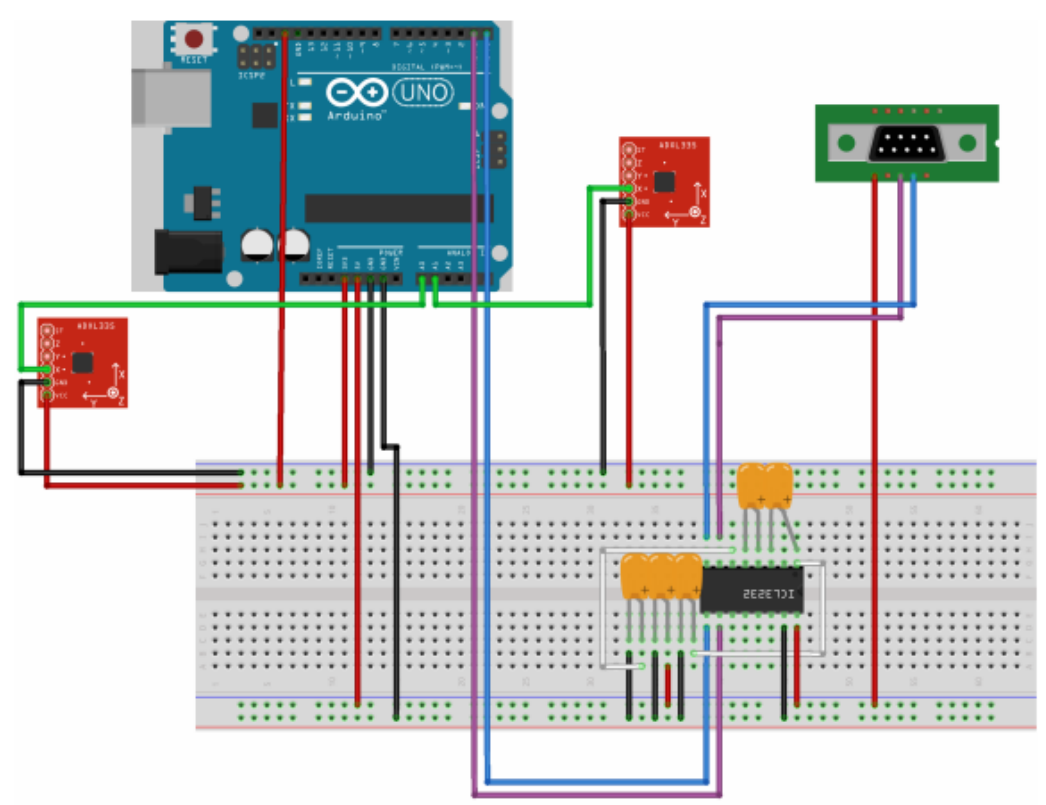

Fig. 3. Vibration Sensor Circuitry

\subsection{Frequency Analysis}

To test the vibration signatures of the machinery used in industries continuously to obtain a standard vibration signature. This standard vibration signature is used as reference. The copper block is attached to the chuck of the experimental lathe and the facing process is carried out at various test cutting speeds, at different feed and depth of cut; when the vibration signatures are captured by the vibration analysis systems. The so obtained vibration signatures are processed by MATLAB to perform Fast Fourier Transforms on the obtained data. 


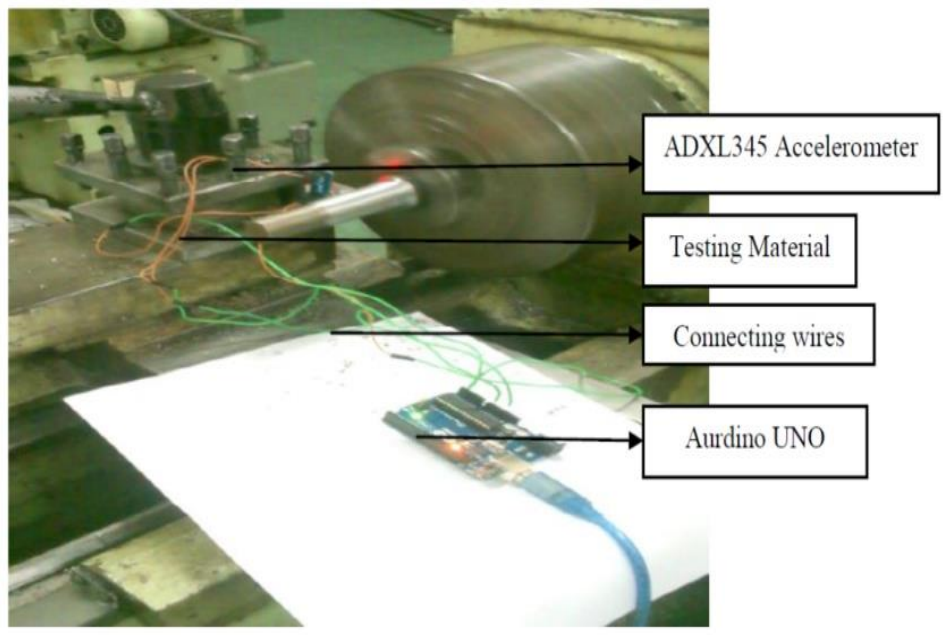

Fig. 4. Industrial Machinery Vibration Analysis

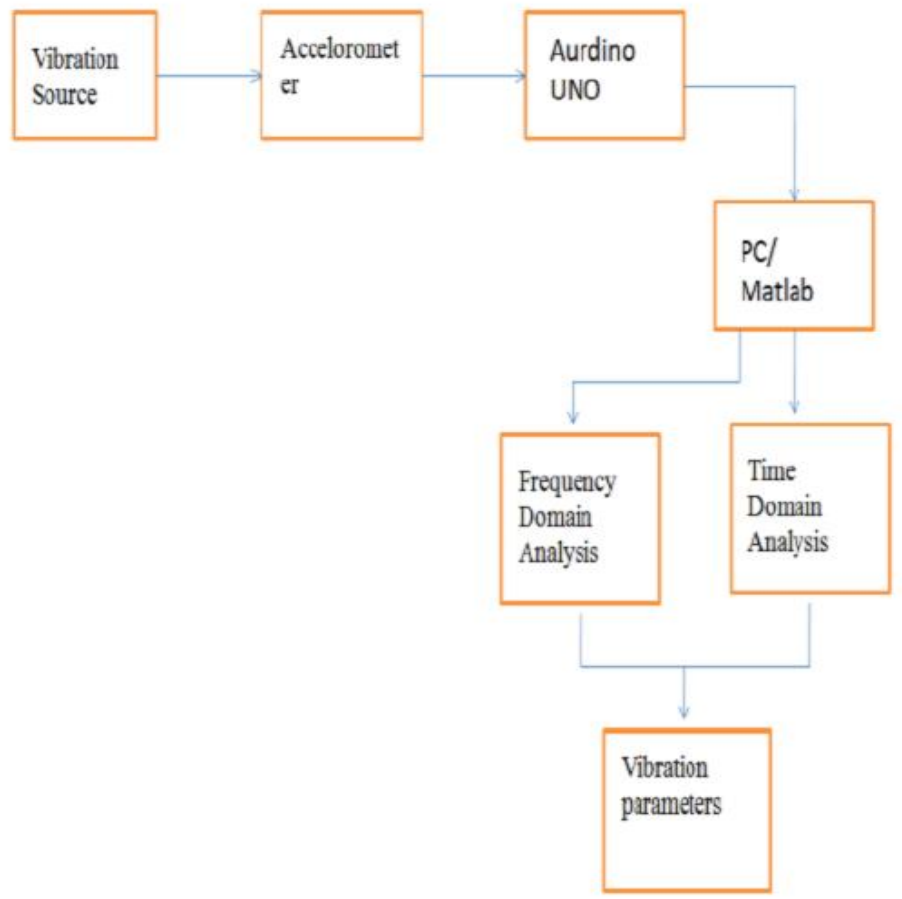

Fig. 5. Method to obtain the Frequency 
The vibration analysis system is composed of accelerometers coupled with Arduino microprocessors to capture vibration signature and the data captured is analyzed by MATLAB software to record the data and serially input the data into the result file stored locally in the computer. The MATLAB program efficiently performs tune and frequency domain calculations; winch can be used for quantitative study and characterization of vibration. By using FFT, the data in time domain - in the form of a table with time stamp with the corresponding voltage output of the accelerometer - is converted to the frequency domain. The following MATLAB command is used:

$$
\text { V1_fft*1 }=\operatorname{abs}\left(\mathrm{fft}\left(\mathrm{V}_{-} \text {time }\right)\right.
$$

The output of the above command is a matrix of voltage represented in the frequency Domain.

$$
f=(0: N-1) /\left(N^{*} T\right)
$$

Here, $\mathrm{N}$ represents the sampling rate in time domain.

\section{Results and Discussions}

The serial monitor program inbuilt in the Arduino package is used to capture and display the data output on the computer. This data is collected by the program called PUTTY to save the acceleration data of the vibrations in all three axis.

\subsection{Vibration Analysis of Industrial Equipment}

The sensor functionality to measure and quantize vibration of Computer Numeric Controlled (CNC) Lathe machine used at M/S Vasmo Technologies Pvt. Ltd. To obtain variation in results, brass and mild steel tools were used and the cutting speed has been altered during operation to obtain variety in results. The various cutting speeds selected were selected according to the operation manual of the lathe machines. While normal cutting speed for the tool piece was up to $1000 \mathrm{rpm}$ the limit of the lathe machine was 800 rpm. The variety of 280,450 and 710 are preset speed on the machines were to act as minimum, moderate and maximum.

The vibration of equipment is studied for a period of five minutes and the collected data is formatted to produce fast Fourier transform, the end result of which is the frequency vs. amplitude graph and the amplitude vs. time graph. The time and frequency response of the vibration is also collected and presented.

The primary functionality performing fast Fourier transforms, plotting time waveforms etc. is to permit a trained engineer, researcher to perform the required vibration analysis in a rapid manner on the required specimen, be it a composite material on a piece of industrial machinery. For example, in industrial equipment has a specific vibration signature which will allow a technician to identify aberrant parts which might be failing or improperly configured, after which corrective action can be taken as appropriate. 


\subsubsection{Results Output}

The output from the accelerometer placed gives vibration in terms of acceleration in all three axis. This data, whether for a composite material or for industrial equipment is processed in Microsoft Excel and then FFT transforms are applied. This is an example of data obtained from industrial equipment, which has been further been processed.

Table 1. Conversion of data from the accelerometer

\begin{tabular}{|l|l|l|l|l|}
\hline $\begin{array}{c}\text { Time } \\
\text { Interval }\end{array}$ & $\begin{array}{c}\text { Real Space } \\
\text { A1 }\end{array}$ & $\begin{array}{c}\text { Real Space } \\
\text { A2 }\end{array}$ & $\begin{array}{c}\text { Processed } \\
\text { A1 }\end{array}$ & $\begin{array}{c}\text { Processed } \\
\text { A2 }\end{array}$ \\
\hline 1 & -45 & -119 & 45 & 119 \\
\hline 2 & -83 & -142 & 83 & 142 \\
\hline 3 & -97 & -180 & 97 & 180 \\
\hline 4 & -18 & -111 & 18 & 111 \\
\hline 5 & -43 & -124 & 43 & 124 \\
\hline 6 & -91 & -147 & 91 & 147 \\
\hline 7 & -132 & -136 & 132 & 136 \\
\hline 8 & -2 & -80 & 2 & 80 \\
\hline 9 & -79 & -101 & 79 & 101 \\
\hline 10 & -82 & -99 & 82 & 99 \\
\hline 11 & -63 & -89 & 63 & 89 \\
\hline 12 & -82 & -109 & 82 & 109 \\
\hline 13 & -80 & -124 & 80 & 124 \\
\hline 14 & -57 & -138 & 57 & 138 \\
\hline
\end{tabular}


3.1.2 Brass Tool time function, characteristics- $280 \mathrm{rpm}$

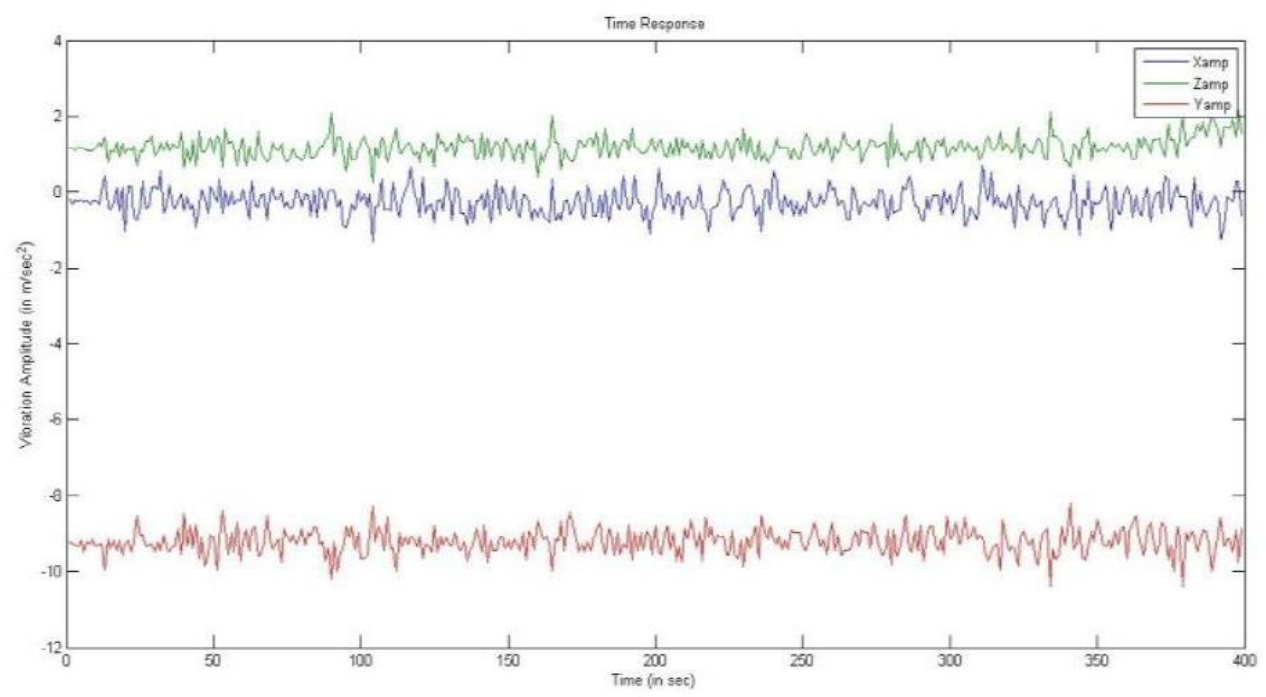

Fig. 6. Brass Tool time function, characteristics- $280 \mathrm{rpm}$

\subsubsection{Mild Steel Tool time function, characteristics- $280 \mathrm{rpm}$}

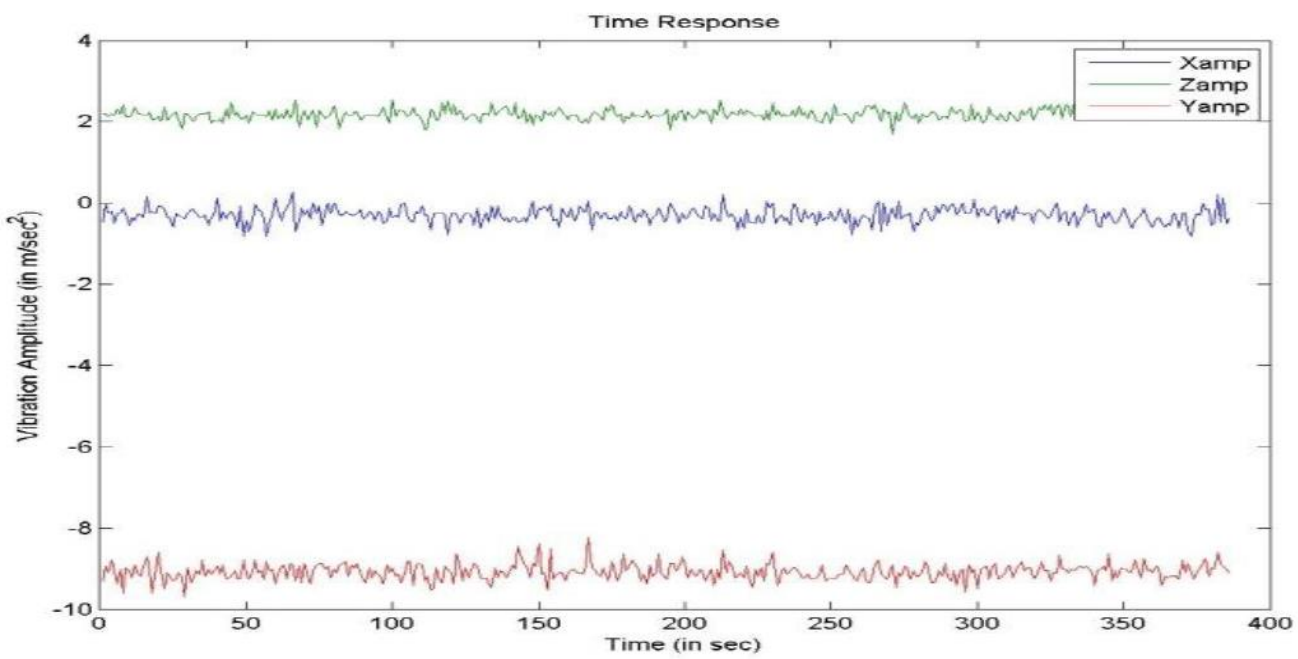

Fig. 7. Mild Steel Tool time function, characteristics- 280rpm

The amplitude of vibration and the frequency are cramped, indicating the proximity of operating equipment vibration with resonance frequency of the equipment. This increases stresses on the equipment and reduces the life of tool and the machinery. In addition to this, such vibrations cause flaw in work piece. Hence, at $280 \mathrm{rpm}$ speed of operation mild steel is selected. 
3.1.4 Brass Tool frequency function, characteristics- $450 \mathrm{rpm}$

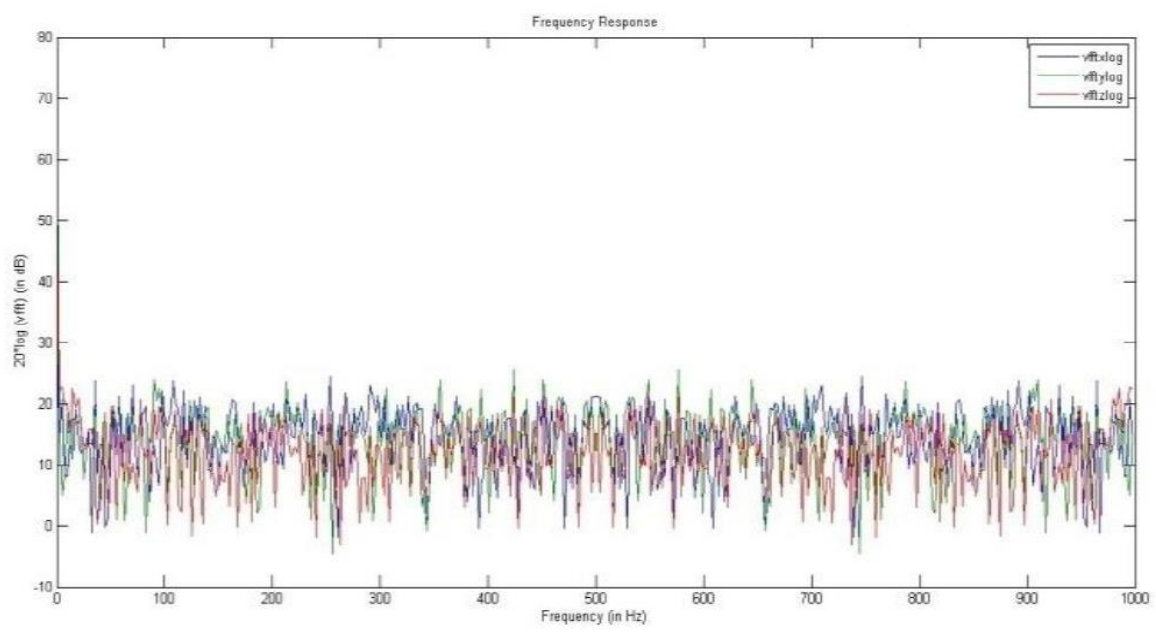

Fig. 8. Brass Tool frequency function, characteristics- $450 \mathrm{rpm}$

3.1.5 Mild Steel frequency function, characteristics- $450 \mathrm{rpm}$

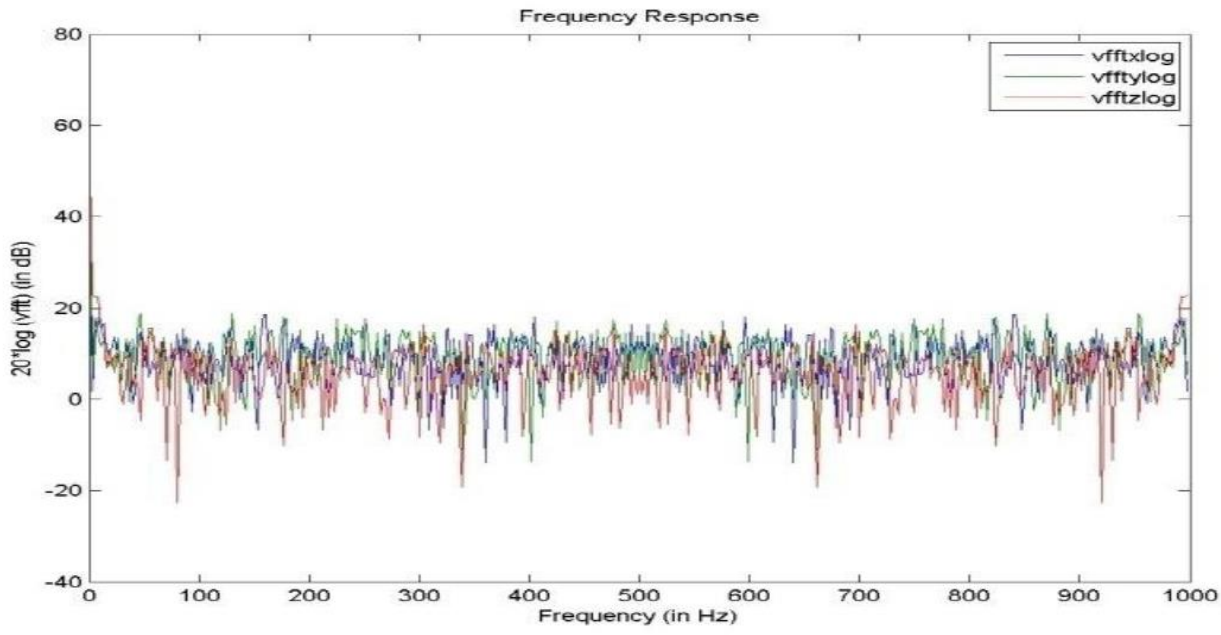

Fig. 9. Mild Steel frequency function, characteristics- 450rpm

The amplitude of vibration and the frequency are packed, indicating the closeness of operating equipment vibration with resonance frequency of the equipment. This increases stresses on the equipment and reduces the life of tool and the machinery. In addition to this, such vibrations cause flaw in work piece. Hence, at $450 \mathrm{rpm}$ speed of operation mild steel is selected. However, this closeness in results can be due to the same material work piece being used. 
3.1.6 Fast Fourier Transforms of Vibration in industrial Equipment:

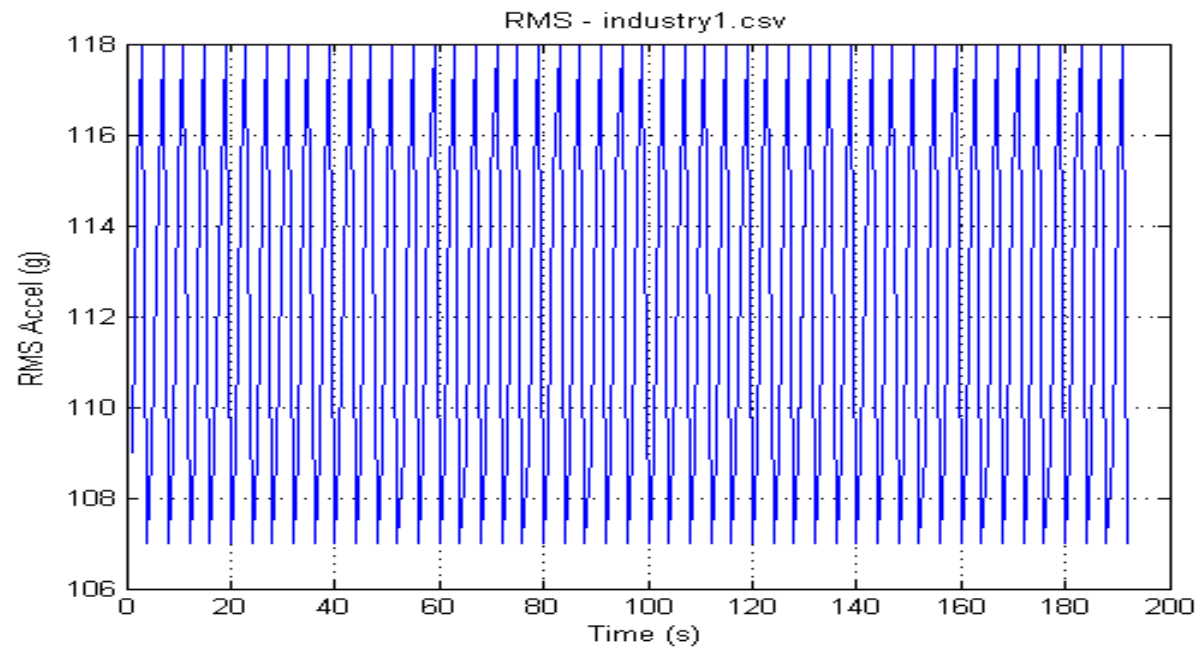

Fig. 10. Amplitude Time Graph of industrial Equipment.

The amplitude time graph shows that the equipment is operating in a stable condition with vibrations within prescribed limits. This graph can be used to detect if there is any fault in the equipment by analyzing outlying data. The above graph is calculated using MATLAB code. This data can be used to determine the limits of normal operation of the equipment and the maximum amplitude limits.

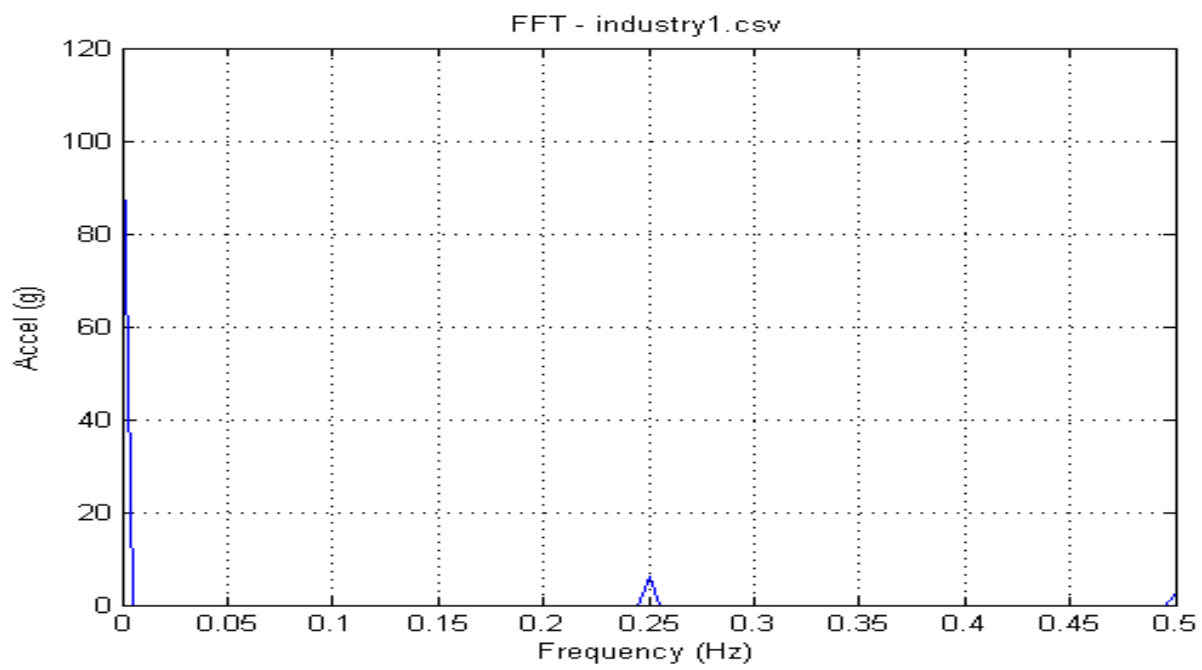

Fig. 11. Amplitude Frequency chart of the vibration of the industrial equipment.

The efficiency of fast Fourier transforms as an algorithm to calculate discrete Fourier transform in on display. The results of the fast Fourier transform in vibration analysis, which is frequency as a function of time to analyze the underlying cause of vibration. Another important advantage of FFT is the frequency resolution is not limited by 
computing power by the sampling rate of the equipment used and the duration for which the test is performed.

\subsection{Vibration analysis of Glass fibre with Al7075 mesh reinforced with epoxy composite:}

The composite material is fabricated according to ASME specifications. A uniform load is applied using a pneumatic plunger through a compressor. The composite material is mounted on the stand and then the load is applied.

The table 2 shows the raw data collected from the vibration produced form the composite material when a uniform load is applied.

Table 2. The raw data collected from the vibration

\begin{tabular}{|c|c|}
\hline Time Interval & Axis 1 \\
\hline 1 & 155 \\
\hline 2 & 127 \\
\hline 3 & 146 \\
\hline 4 & 142 \\
\hline 5 & 132 \\
\hline 6 & 152 \\
\hline 7 & 122 \\
\hline 8 & 160 \\
\hline 9 & 122 \\
\hline 10 & 151 \\
\hline 11 & 134 \\
\hline 12 & 138 \\
\hline 13 & 148 \\
\hline 14 & 125 \\
\hline 15 & 155 \\
\hline
\end{tabular}

The above is the serial data obtained from the Arduino microprocessor. This data is then imported to the MATLAB software and then fast Fourier transforms and other such vibration analysis data is shows. 
Failure analysis of composite material is more tedious compared to analysis of physical properties of composite materials as discussed so far. Failure mechanism of composite material, which is a function of temperature and load is difficult to simulate and is analogous to occurrences of micro fractures which have to be studied visually using an electron microscope. This vibration analysis is extremely important for fatigue testing of composite materials, to determine the maximum amplitude at which the failure of the composite material takes place.

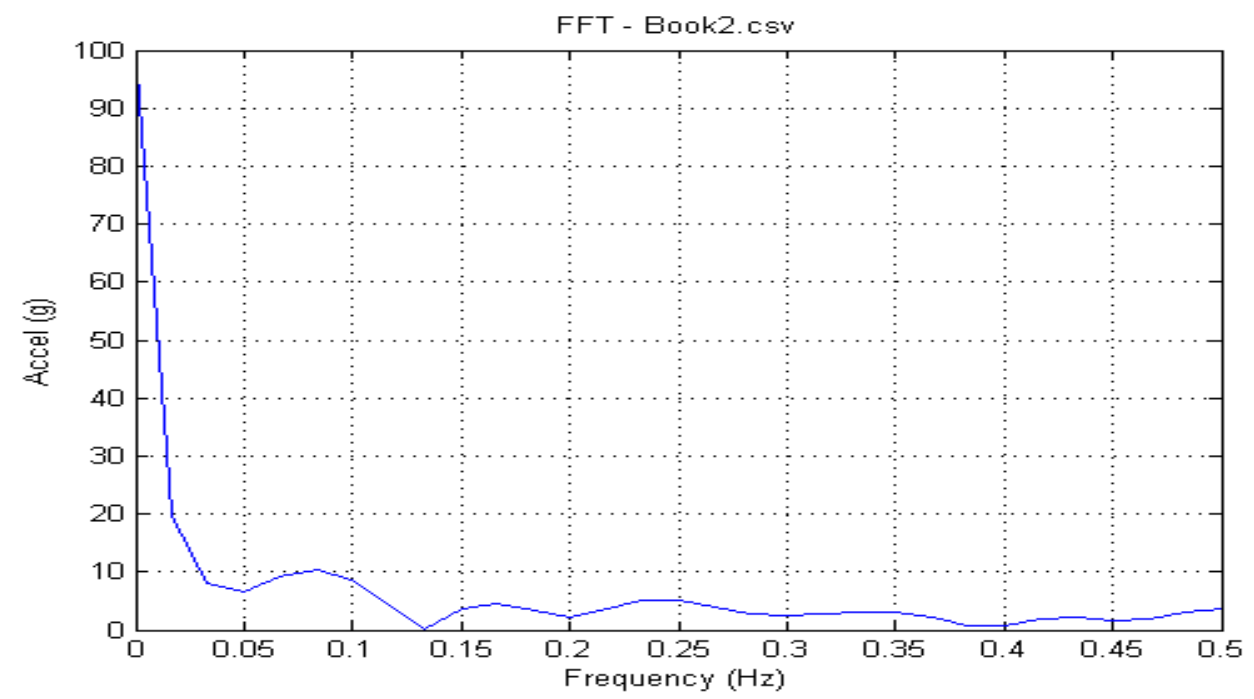

Fig. 12. FTT in Mat Lab Frequency vs. Acceleration

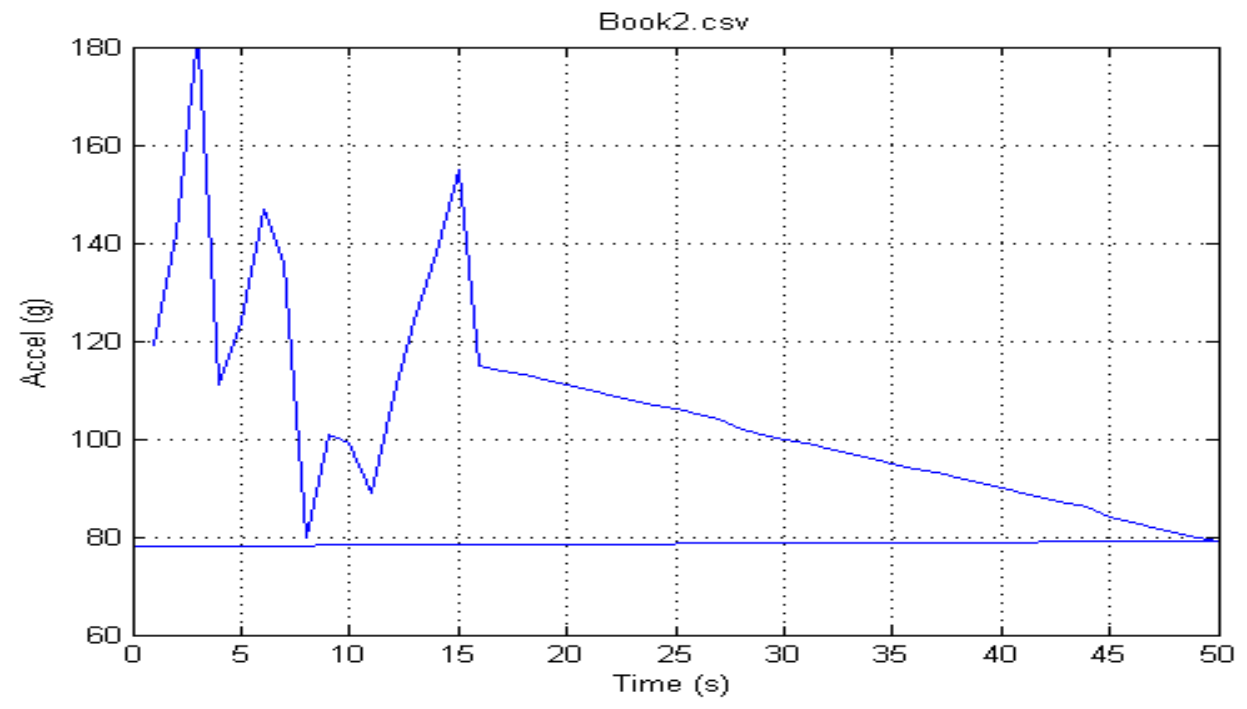

Fig. 13. FTT in Mat Lab Time vs. Acceleration

The above is the serial data obtained from the Arduino microprocessor. This data is then imported to the MATLAB software and then fast Fourier transforms and other such 
vibration analysis data is shows. This vibration analysis is extremely important for fatigue testing of composite materials, to determine the maximum amplitude at which the failure of the composite material takes place. The blue line shows the acceleration data corresponding to vibration about the vertical axis, i.e. the vibration about the y axis.

\section{Conclusions}

In this study we analyze the structural vibrational characteristics of brass, mild steel and GFRP with AL7075. The composite material is fabricated according to ASTM standards. The vibrational properties of composite materials and industrial machinery are captured using Arduino open source microcontroller and accelerometer and a stand has been designed to hold the specimen. The data is processed in MATLAB using ARDUINO relayed to computer to convert the data to frequency spectra using Fast-Fourier transforms (FFT).Vibrational properties of two lathes are compared at different conditions and quantified the vibration results using Fast Fourier Transforms (FFT) algorithm. In addition to which, the vibration signatures of a composite is studied. We also analyzed the vibration signature to identify the faults in industrial equipment.

\section{References}

1. M. Chandrashekhar, Ranjan Ganguli. Nonlinear vibration analysis of composite laminated and sandwich plates with random material properties. International, Volume 52, Issue 7, Pages 874-891. (July 2010)

2. Jonathan Young C. Vibration Analysis Using a MEMS Accelerometer. Thesis and dissertation

3. Zani Ghemari, Salah Saad. Development of Model and Enhancement of Measurement Precision of Sensor Vibration. IEEE Sensors Journal. Volume 12, Issue 12, Pages 3454 - 3459. (Dec. 2012)

4. GJ Sheu, SM Yang, W.L. Huang. Simulating Displacement and Velocity Signals by Piezoelectric Sensor in Vibration Control Applications. Smart Materials Research Volume 2012, Article ID 390873. (2012)

5. R.C.M. Yamp.W. Tsel. Lip. Tu,Intelligent Predictive Decision Support System for Condition-Based Maintenance Technology. The International Journal of Advanced Manufacturing Technology, Volume 17, Issue 5, Pages 383-391. (Feb.2001)

6. S Ebersbach, Z Peng, N J Kessissoglou .The investigation of the condition and faults of a spur gearbox using vibration and wear debris analysis techniques. WEAR, Volume 260, Issues 1-2, Pages 16-24.(Jan. 2006)

7. Han B, Sun S, Ding S, Zhang L, Yu X, Ou J. Review of nanocarbon-engineered multifunctional cementitious composites. Composites. Part A: Applied Science and Manufacturing. Volume 70, Pages 69-81. (Mar. 2015)

8. Abu Al-Rub RK, Ashour AI, Tyson BM. On the aspect ratio effect of multi-walled carbon nanotube reinforcements on the mechanical properties of cementitious nano composites. Construction and Building Materials. Volume 35, Pages 647-655. (Oct. 2012)

9. Konsta-Gdoutos MS, Aza CA. Self-sensing carbon nanotube (CNT) and nanofiber (CNF) cementitious composites for real time damage assessment in smart structures. Cement and Concrete Composites. Volume 53, Pages 162-169. (Oct. 2014)

10. Parveen S, Rana S, Fangueiro R.A Review on Nanomaterial Dispersion, Microstructure, and Mechanical Properties of Carbon Nanotube and Nanofiber 
Reinforced Cementitious Composites. Journal of Nanomaterials. Volume 2013, Article ID 710175 (July. 2013) 